\title{
Penyuluhan Koperasi Petani Jeruk di Nagari Koto Tinggi Kecamatan Gunung Omeh Kabupaten Limapuluh Kota
}

\author{
Weriantoni, Erizal Nazaruddin, Lukman, Amra Ausri, Khadijah, Nurul Fadhilah, \\ Rahmat Fadhilah, dan Elva Yulianti \\ Fakultas Ekonomi, Universitas Andalas, Kampus II Payakumbuh. Indonesia \\ E-mail: weriantoni@eb.unand.ac.id
}

Keywords: community service,

counseling, cooperative formation

Kata Kunci: pengabdian masyarakat, penyuluhan, pembentukan koperasi

\begin{abstract}
This service aims to introduce the concept and utilization of cooperatives to citrus farmers in Gunung Omeh District, Limapuluh Kota Regency. The method used was the lecture method (counseling) and training. There were many farmers who do not know about cooperatives, cooperative objectives, cooperative benefits and how the cooperative formation process and willing to form a cooperative formation committee. It was hoped that the government can help the farmers to establish an cooperative system.
\end{abstract}

\begin{abstract}
ABSTRAK
Pengabdian ini bertujuan untuk memperkenalkan tentang konsep dan pemanfaatan koperasi kepada petani jeruk di Kecamatan Gunung Omeh Kabupaten Limapuluh Kota. Metode yang digunakan adalah metode ceramah (penyuluhan) dan pelatihan. Terdapat banyak petani yang belum mengetahui tentang koperasi, tujuan koperasi, manfaat koperasi dan bagaimana proses pembentukan koperasi dan bersedia membentuk panitia pembentukan koperasi. Maka terbentuk koperasi petani yang diketuai oleh Datuak Godang. Diharapkan pemerintah bisa membantu pendirian

koperasi petani jeruk ini.
\end{abstract}

\section{PENDAHULUAN}

Berikut ini merupakan potensi tanaman buah jeruk yang dimiliki oleh Kabupaten Lima Puluh Kota dimana Kecamatan Gunung Omeh pada peringkat pertama dalam memberikan kontribusi terhadap buah jeruk yaitu sebesar 96,05 persen. Berdasarkan data Tabel 1 dapat dilihat bahwa daerah Kabupaten Limapuluh Kota yang menghasilkan buah jeruk terbesar adalah di Nagari Koto Tinggi Kecamatan Gunung Omeh. Dimana kontribusi rata-rata buah jeruknya untuk Kabupaten Lima Puluh Kota sebesar 96,05\% dari total produksi buah jeruk (Limapuluh Kota Dalam Angka, 2017). Ini berarti bahwa hampir seluruh produksi jeruk berada di Kecamatan Gunung Omeh. Sehingga perlu dijaga dan dikembangkan lagi (Srivani dkk, 2018). Jeruk Kabupaten Limapuluh Kota ini sudah terkenal di Provinsi Sumatera Barat. Sesuai daerah penghasilnya, jeruk ini dinamakan dengan jeruk siam gunung omeh (JESIGO). 
Tabel 1. Hirarki Potensi Tanaman Jeruk di Kabupaten Limapuluh Kota

\begin{tabular}{lcc}
\hline \multicolumn{1}{c}{ Kecamatan } & $\begin{array}{c}\text { Nilai Kontribusi } \\
\text { Rata-rata }\end{array}$ & Tingkat Kepotensial \\
\hline Gunung Omeh & 96.05 & I \\
Suliki & 1.25 & II \\
Bukik Barisan & 0.63 & III \\
Harau & 0.39 & IV \\
Guguak & 0.38 & V \\
Lareh Sago Halaban & 0.32 & VI \\
Luak & 0.25 & VII \\
Situjuah Limo Nagari & 0.25 & VIII \\
Pangkalan Koto Baru & 0.24 & IX \\
Akabiluru & 0.11 & X \\
Mungka & 0.07 & XI \\
Kapur IX & 0.07 & XII \\
Payakumbuh & 0.01 & XIII \\
\hline
\end{tabular}

(Sumber: BPS, 2017)

Namun dibalik kepopuleran dan permintaan yang tinggi terhadap jeruk Gunung Omeh (JESIGO) khusus jeruk Nagari Koto Tinggi ini terdapat beberapa masalah yaitu pertama adalah panen / produksi buah jeruknya hampir secara bersamaan sehingga produksi jeruk menjadi berlimpah dan banyak. Hal ini menyebabkan kelebihan penawaran. Sehingga harga buah jeruk menjadi sangat rendah dan petani mengalami kekurangan keuntungan serta bahkan bisa menyebabkan kerugian. Kedua adalah pembeli/penadah buah jeruk yang paling banyak adalah para agen-agen jeruk sehingga penetapan harganya ditetapkan oleh para agen jeruk tersebut dan harga juga rendah. Jadi petani jeruk tidak mempunyai kekuatan dalam menetapkan harga. Ketika panen jeruk yang dilakukan dua kali seminggu yaitu hari Senin dan hari Jumat, para agen sudah menunggu petani jeruk di kebun.

Permasalahan yang ketiga adalah belum adanya koperasi yang menaungi petani jeruk. Koperasi merupakan organisasi ekonomi rakyat yang berwatak sosial dan beranggotakan orangorang, badan-badan hukum koperasi yang merupakan tata susunan ekonomi sebagai usaha bersama berdasarkan atas asas kekeluargaan. Dengan adanya koperasi petani jeruk, maka diharapkan bisa meningkatkan kesejahteraan petani, menjaga kestabilan harga buah jeruk agar tidak turun terus, menjaga kesediaan stok pupuk dan pestisida besertanya kestabilan harganya.

Telah banyak upaya yang telah dilakukan oleh pemerintah yaitu bantuan kepada petani jeruk untuk meningkatkan produksi jeruk yang dilakukan oleh dinas pertanian. Usaha ini termasuk sukses karena produksi jeruk meningkat. Namun tidak diiringi dengan konsep pemasaran buah jeruk tersebut. Hal inilah yang menjadi salah satu yang membuat harga jeruk jatuh di tingkat petani.

\section{Tujuan Kegiatan}

Tujuan kegiatan pengabdian ini adalah pertama: untuk memperkenalkan tentang konsep koperasi, prinsip koperasi dan pemanfaatan koperasi kepada petani jeruk di Nagari Koto Tinggi Kecamatan Gunung Omeh Kabupaten Lima Puluh Kota. Kedua: pembentukan anggota panitia pembentukan pengurus koperasi petani jeruk Nagari Koto Tinggi, ketiga: pembentukan pengurus koperasi petani jeruk Nagari Koto Tinggi.

\section{Ruang Lingkup Kegiatan}

Supaya pengabdian ini terarah dengan baik, maka pelaksana kegiatan membuat ketentuan utama sebagai berikut: 
a. Peserta berasal dari petani jeruk di Nagari Koto Tinggi Kecamatan Gunung Omeh Kabupaten Lima Puluh Kota dan pelatihan ini berkerja sama dengan dinas perdagangan, industri dan koperasi Kabupaten Limapuluh Kota.

b. Pengabdian dan pelatihan diadakan selama lima minggu dengan metode ceramah, penyuluhan dan pelatihan.

\section{METODE}

\section{Lokasi Kegiatan}

Kelompok petani jeruk di Jorong Sungai Dadok Nagari Koto Tinggi Kecamatan Gunung Omeh Kabupaten Lima Puluh Kota, Sumatera Barat.

\section{Uraian Kegiatan}

Kegiatan pengabdian petani jeruk di Nagari Koto Tinggi Kecamatan Gunung Omeh Kabupaten Lima Puluh Kota dilaksanakan dalam empat tahap, yang terdiri dari tahap persiapan, tahap pelatihan, tahap evaluasi dan tahap pembuatan laporan.

1. Tahap Persiapan

Pada tahap ini dilakukan antara lain: persiapan materi, mengunjungi lokasi dan mengurus perizinan ke kantor kenagarian tentang jadwal pelaksanaan, tempat pelaksanaan, peserta dan hal lain-lain yang terkait dengan kegiatan ini. Tahap persiapan ini dilakukan pada minggu I (pertama).

2. Tahap Pelaksanaan Kegiatan

Pelaksanaan kegiatan pelatihan ini dilaksanakan selama 5 hari yaitu pada minggu ke-2 sampai dengan minggu ke-5.

3. Tahap Evaluasi

Setelah tahap pemberdayaan dan pelatihan dilaksanakan evaluasi terhadap kegiatan yang telah dilakukan. Evaluasi dilakukan pada minggu ke-6 dan ke-7.

4. Tahap Pembuatan Laporan

Kegiatan pengabdian masyarakat ini diakhiri dengan pembuatan laporan yang mencakup seluruh aspek yang terkait dengan pengabdian ini. Pembuatan laporan dilaksanakan pada minggu ke-8

\section{Metode}

Untuk mencapai tujuan meningkatnya pengetahuan petani jeruk di Nagari Koto Tinggi Kecamatan Gunung Omeh Kabupaten Lima Puluh Kota tentang konsep koperasi dan pemanfaatannya, maka metode yang digunakan adalah:

1. Metode Ceramah dan Penyuluhan

Metode ceramah dan penyuluhan bertujuan memberikan pengertian dan pemahaman tentang bagaimana konsep dan pemanfaatan koperasi yang mempunyai tujuan mensejahterakan anggotanya.

2. Metode Pelatihan

Metode pelatihan dilaksanakan setelah selesai dilakukan metode ceramah/ penyuluhan dan metode diskusi. Metode ini bertujuan memberikan penyuluhan dan pelatihan bagaimana cara membuat dan membentuk koperasi petani jeruk. Setelah dilakukakan penyuluhan tentang koperasi, azas koperasi, sistem koperasi, manfaat koperasi dan bagaimana pelaksanaanya. Maka dibentuk sebuah koperasi petani jeruk dimana anggotanya adalah semua petani jeruk di Nagari Koto Tinggi Kecamatan Gunung Omeh Kabupaten Lima Puluh Kota. 


\section{HASIL DAN PEMBAHASAN}

\section{Pengetahuan Tentang Koperasi}

Peningkatan pengetahuan tentang koperasi, tujuan koperasi, manfaat koperasi dan bagaimana proses pembentukan koperasi. Hal ini tercermin ketika petani jeruk sangat antusias membentuk koperasi setelah ada penyuluhan tentang koperasi.

2. Pembentukan Panitia Pembentukan Koperasi

Diadakannya rencana rapat untuk penetapan pengurus koperasi petani jeruk sehingga akan ada pengurus koperasi dan pada akhirnya akan berdiri sebuah koperasi.

3. Adanya terbentuk calon pengurus koperasi petani jeruk yaitu: Ketua: Datuk Godang, Wakil Ketua: Rici Chandra, Sekretaris 1: R. F. Imam Mudo, Sekretaris 2: Fahrur Rozi, Bendahara: M. Imam Mudo.

Dengan rendahnya nilai jual jeruk ditingkat petani dan sulitnya mendapatkan pupuk maka banyak petani jeruk ini ingin membuat koperasi petani jeruk. Harga ditingkat petani sangat rendah hal inilah yang membuat susah untuk membeli kebutuhan jeruk tersebut seperti pupuk dan pestisida agar buah jeruk tidak kena hama. Hal yang membuat harga jeruk ini rendah adalah karena petani jeruk tidak bisa menentukan harga jeruk itu sendiri karena yang menentukan harga jeruk adalah pengempul (tengkulak). Hal ini terjadi karena banyak petani yang meminjam uang terlebih dahulu kepada pengempul/tengkulak untuk kebutuhan keluarga seperti biaya untuk anak sekolah/kuliah, dan untuk biaya pembelian pupuk dan pestisida.

Selain harga, susahnya mendapatkan pupuk dan pestisida juga menjadi masalah bagi petani jeruk. Selain harga pupuk yang mahal ternyata ketersediaan pupuk juga susah ditemukan di pasar. Kemudian pestisida untuk jeruk juga harganya cukup mahal. Hal ini juga menjadi masalah bagi petani. Hal ini disampaikan oleh para petani jeruk yang ada di Nagari Koto Tinggi.

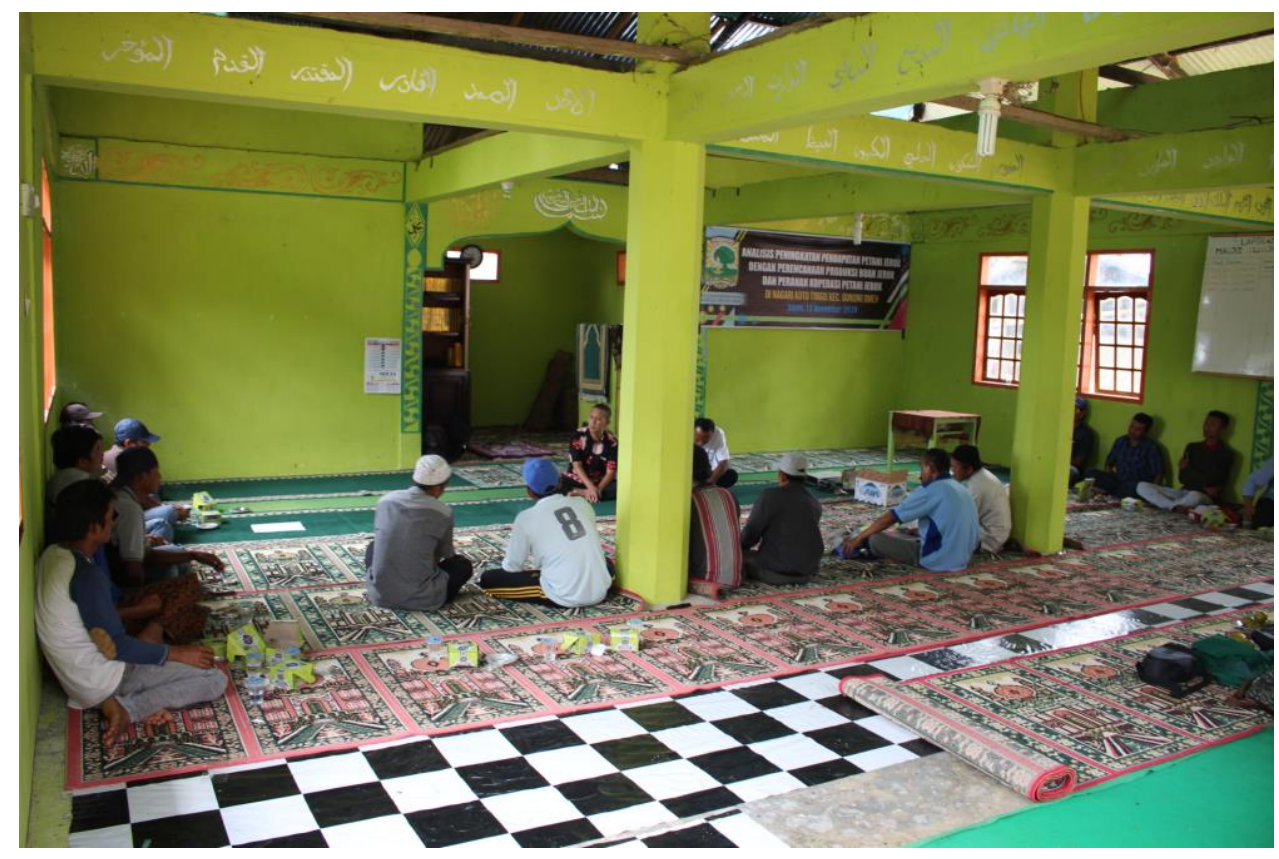

Gambar 1. Para petani menyampaikan permasalahan-permasalahan yang dihadapi

Berdasarkan permasalahan-permasalahan yang disampaikan oleh petani jeruk. Maka kami dengan tim merumuskan salah satu solusinya adalah dengan pembentukan dan pembuatan koperasi petani jeruk. Dimana koperasi ini tujuannya adalah untuk kesejahteraan anggotanya. Nanti apabila terbentuk koperasi maka diharapkan adalah harga tidak rendah lagi, pupuk tersedia dan harga terjangkau serta pestisida juga harganya nanti relatif lebih murah dibandingkan dengan harga yang ada di pasar. Hal ini bisa meningkatkan kesejahteraan petani. 


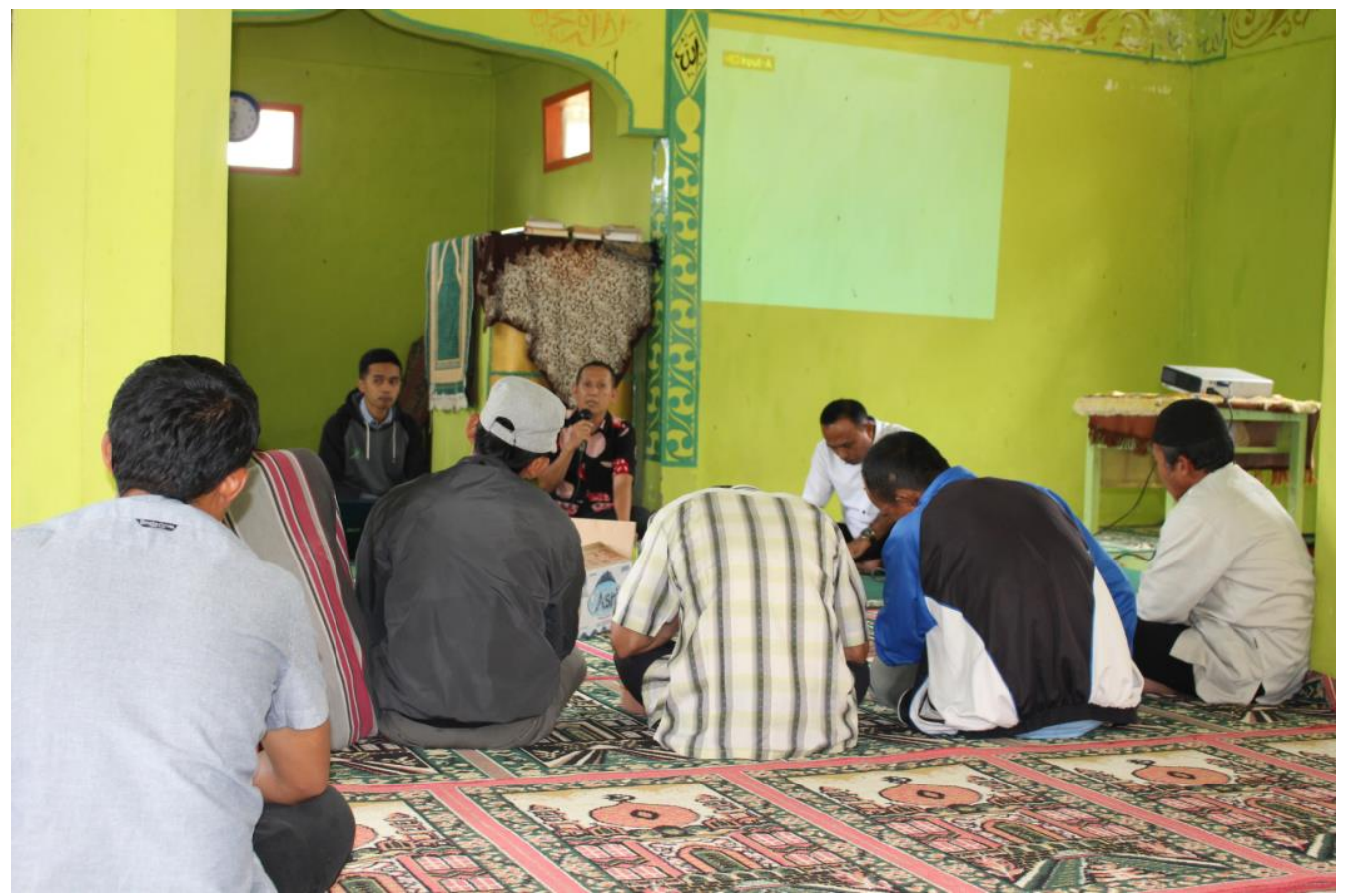

Gambar 2. Penjelasan tahapan kegiatan oleh ketua pengabdian kepada masyarakat

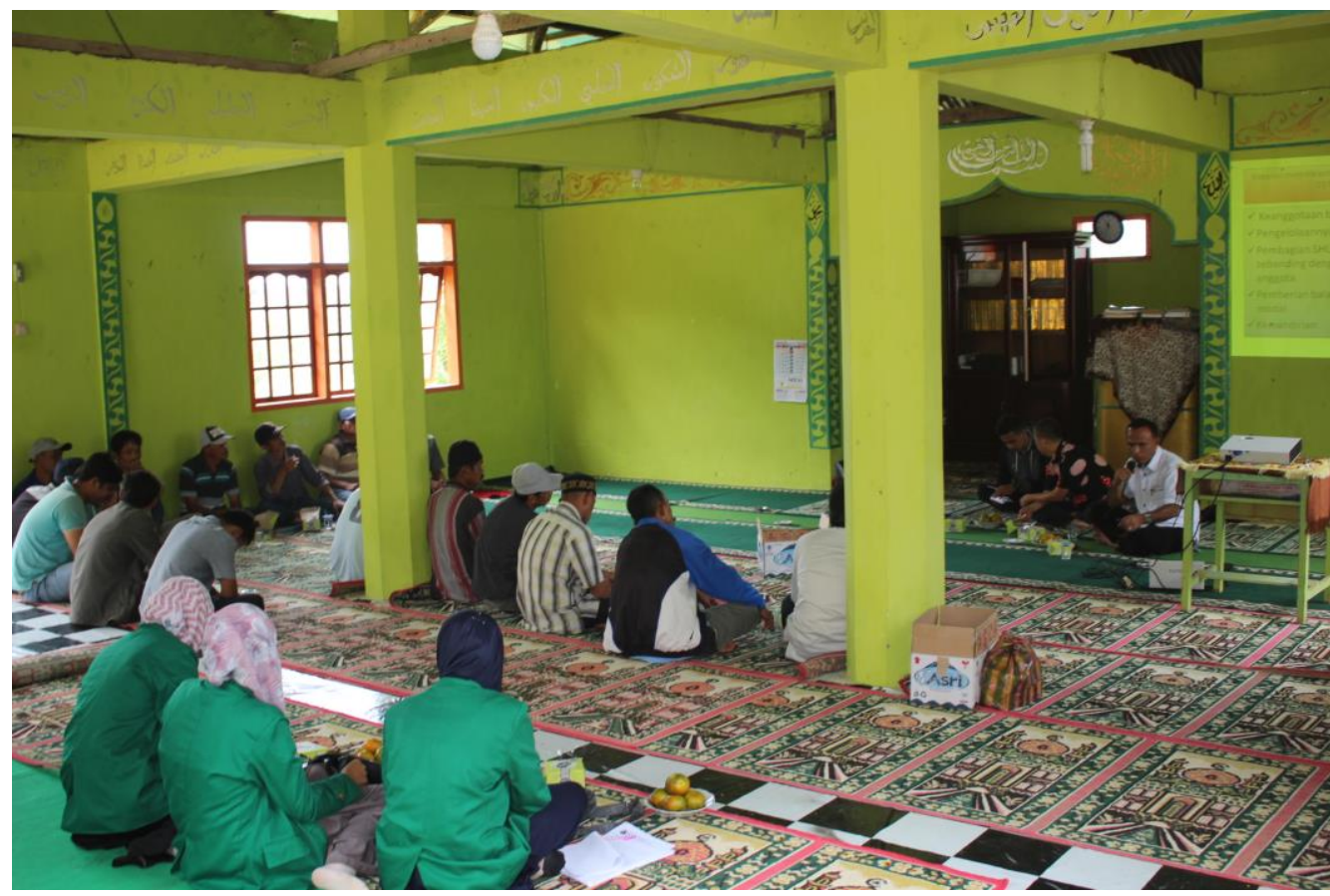

Gambar 3. Penyampaian tentang konsep koperasi oleh Bapak Erizal. N, S.E., M.M yang merupakan staf pengajar mata kuliah Koperasi sekaligus sebagai anggota tim koperasi

Setelah penyampaian materi koperasi oleh Bapak Erizal. N, S.E., M.M maka petani jeruk sangat antusias untuk membuat suatu koperasi. Untuk itu maka bersama-sama tim pengabdi dan petani jeruk merintis pembuatan koperasi di Nagari Koto Tinggi. Dengan musyarawarah untuk mufakat maka terbentuklah tim pengurus koperasi petani. 


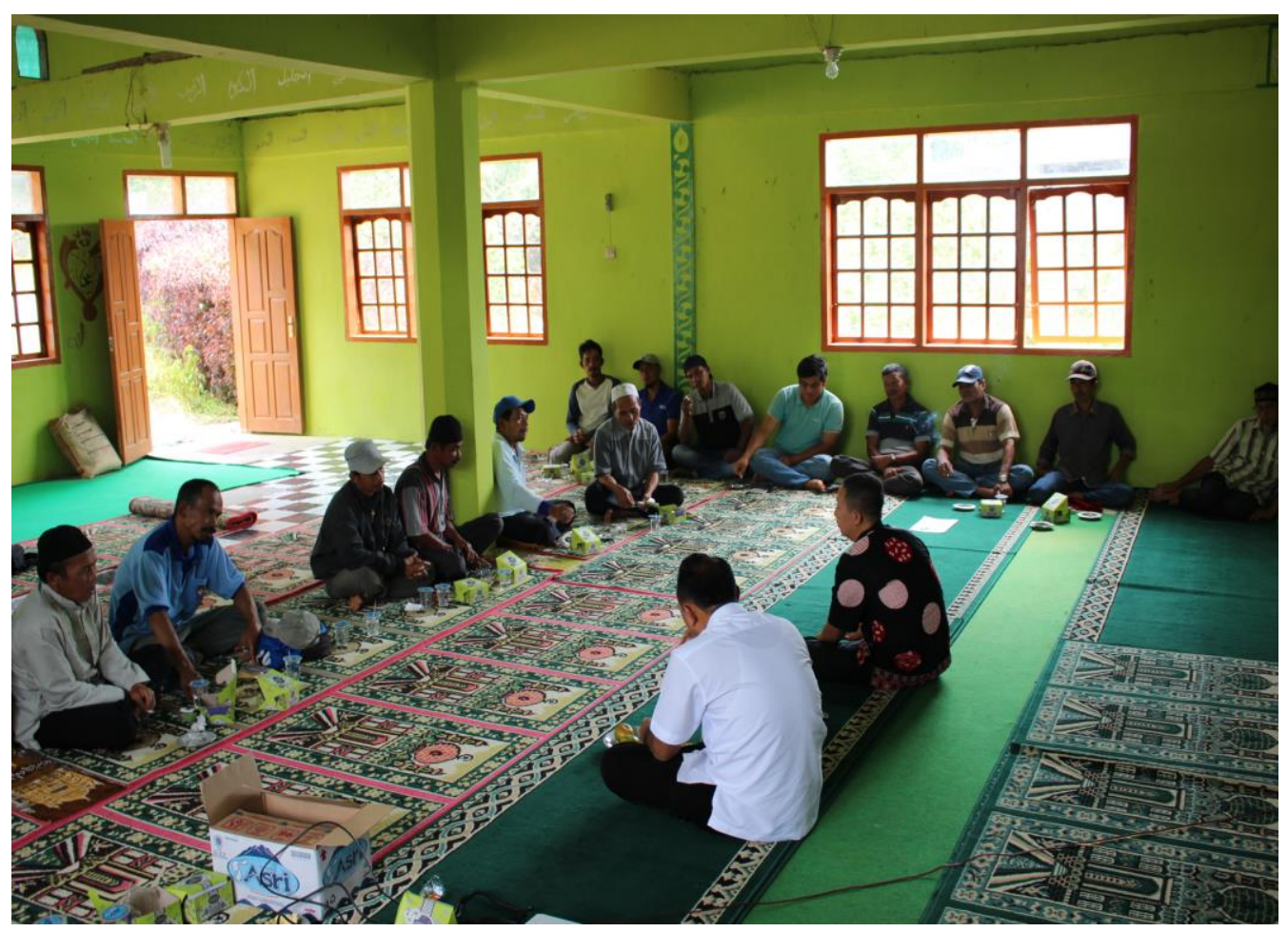

Gambar 4. Musyawarah untuk mencari pengurus koperasi

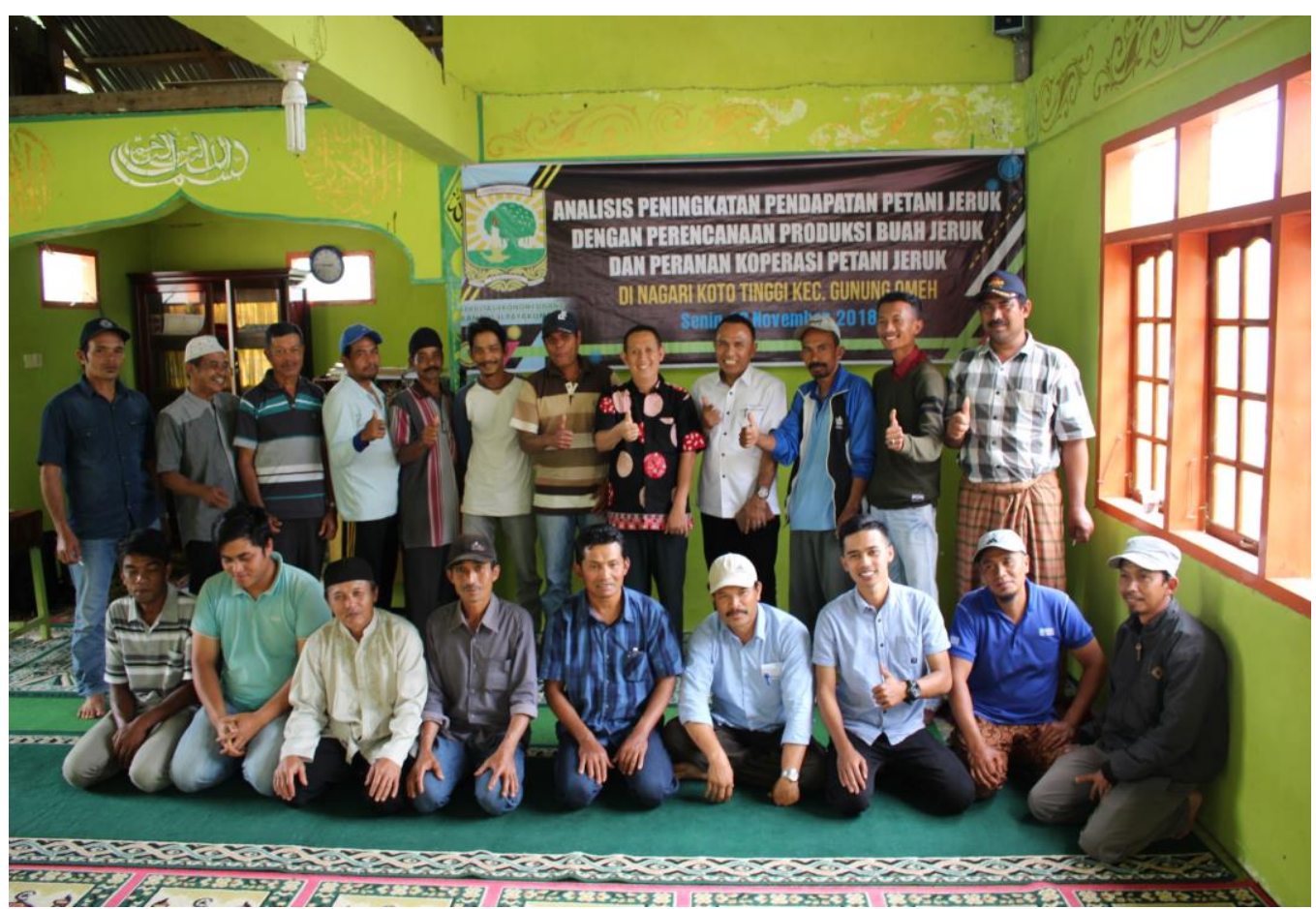

Gambar 5. Foto bersama petani jeruk 


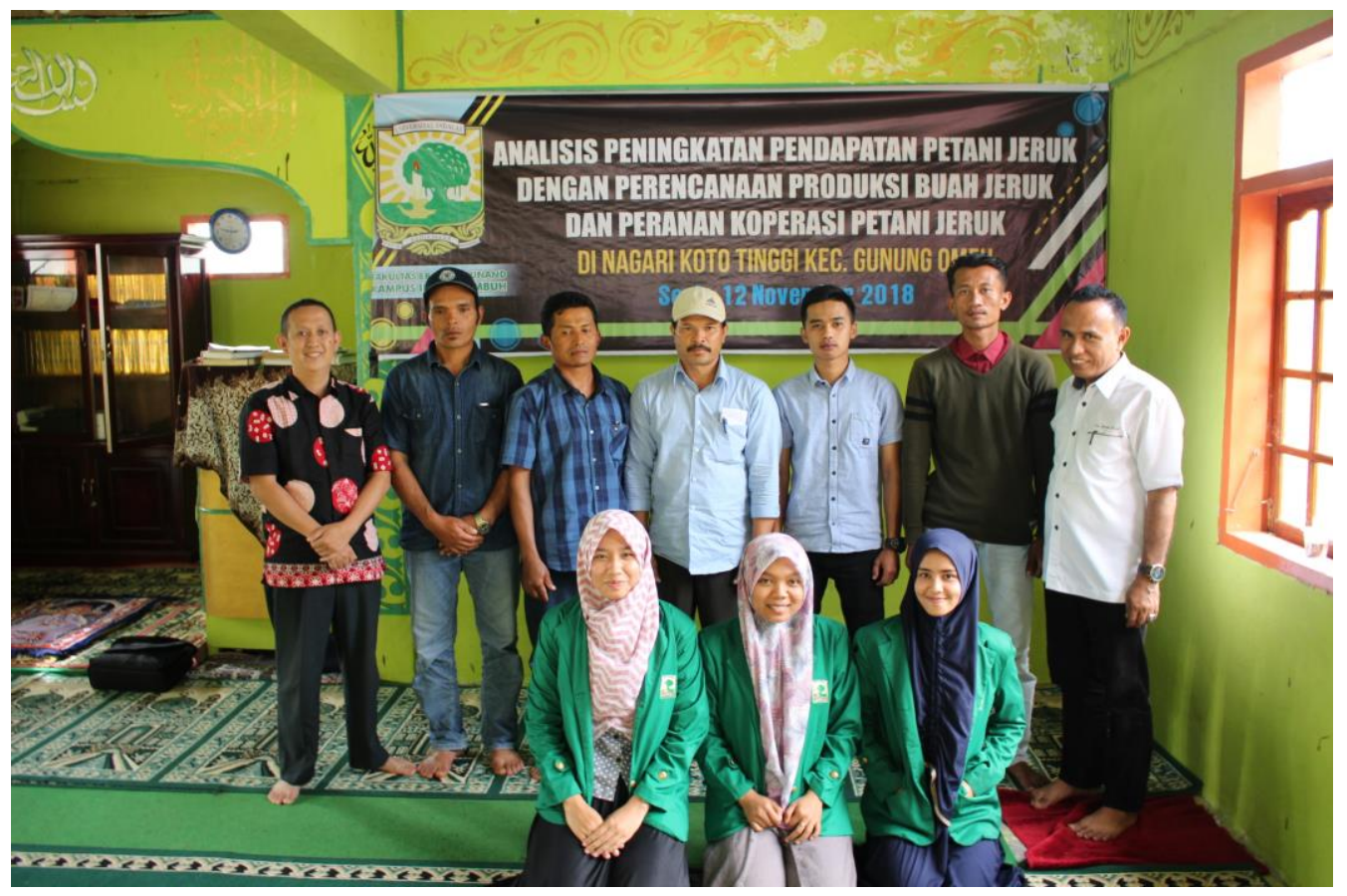

Gambar 5. Foto bersama dengan pengurus koperasi petani jeruk Nagari Koto Tinggi

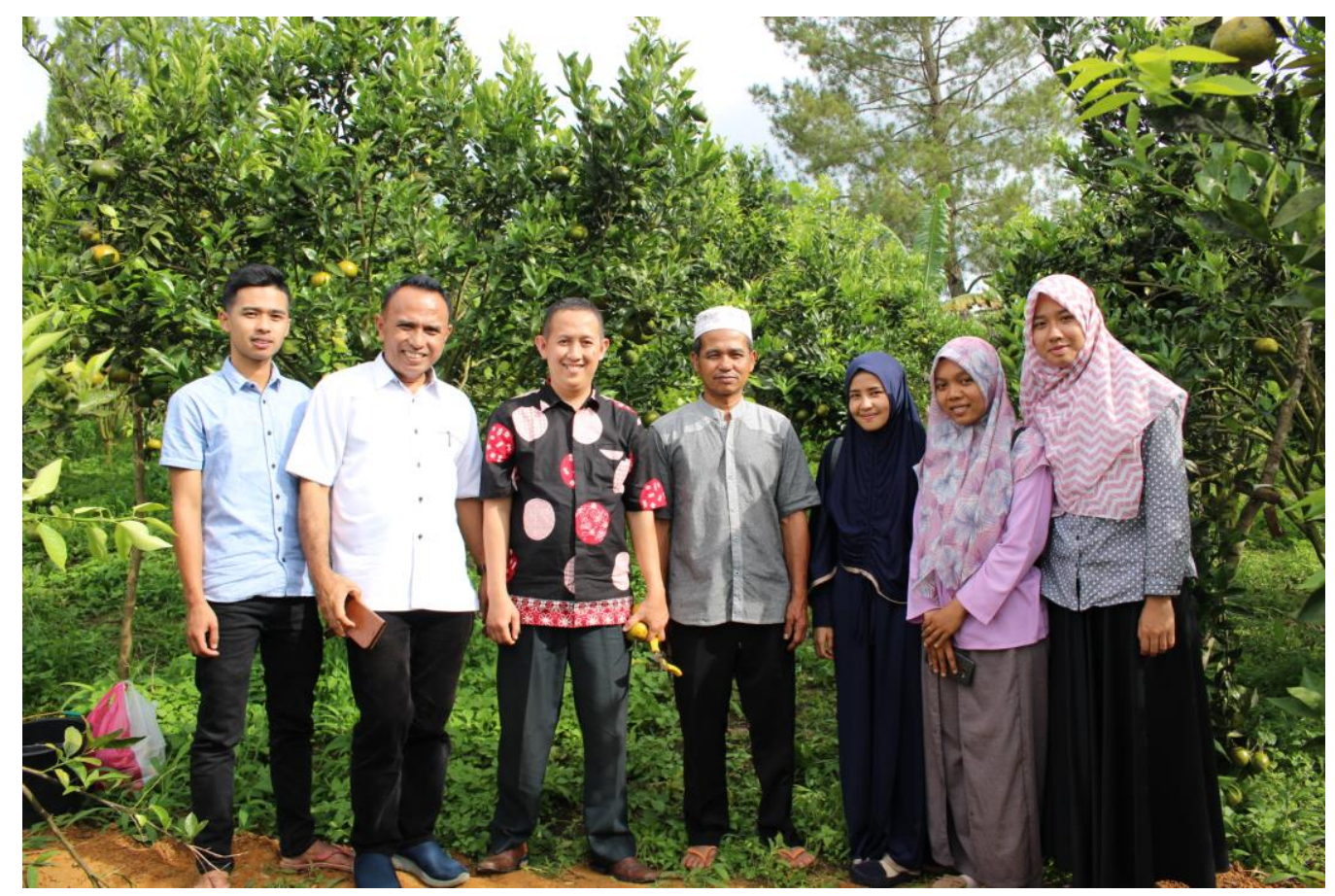

Gambar 6. Kebun Jeruk Siam Gunung Omeh (JESIGO)

\section{KESIMPULAN DAN SARAN}

\section{Kesimpulan}

1. Petani jeruk belum mengetahui tentang koperasi, tujuan koperasi, manfaat koperasi dan bagaimana proses pembentukan koperasi.

2. Petani jeruk bersedia akan membentuk koperasi petani jeruk. Setelah penyuluhan ini maka terbentuklah sebuah koperasi petani jeruk yang diketuai oleh Datuk Godang.

3. Calon Pengurus Koperasi Petani yaitu Ketua: Datuk Godang, Wakil Ketua: Rici Chandra, Sekretaris 1: R. F. Imam Mudo, Sekretaris 2: Fahrur Rozi, Bendahara: M. Imam Mudo. Kemudian pengurus ini akan didaftarkan ke Dinas Perdagangan, Koperasi, Usaha Kecil dan Menengah. 


\section{Saran}

1. Diharapkan pemerintah membantu dalam pembuatan sinyal komunikasi karena sinyall komunikasi di daerah ini tidak ada.

2. Buat calon anggota koperasi.

\section{UCAPAN TERIMA KASIH}

Kami ucapkan terima kasih kepada Wali Nagari Koto Tinggi, Kepala Jorong Sungai Dadok, semua kepala jorong yang terlibat, petani jeruk Nagari Koto Tinggi, Pak Erizal N, SE, MM, mahasiswa Prodi Ekonomi Pembangunan Fakultas Ekonomi Universitas Andalas Kampus II Payakumbuh.

\section{DAFTAR PUSTAKA}

BPS. 2017. Lima Puluh Kota dalam Angka. Sarilamak. Sumatera Barat.

Hendrojogi, Koperasi, Azas-Azas, Terori dan Praktek, Raja Grafindo Jakarta.

Srivani, musbatiq dkk. 2018. Analisis Potensi Ekonomi Dalam Strategi Pembangunan Dan Pengembangan Wilayah Kabupaten Lima Puluh Kota. JEP Vol. 7 No. 3. November 2018 Unila. Lampung.

Sulistiyani, Ambar Teguh. Kemitraan dan Model-Model Pemberdayaan, Gava Media Yogyakarta. 